\title{
A TRUE SCIENTIST
}

Science, like art, can be inspiring and full of beauty, within a context that permits its development, inevitably at the cost of voluntary effort, based on reason shaped by experience. Carlos da Silva Lacaz, both as a scientist and as a man, gives us cause for serious reflection as an example of the unifying method when the diverse aspects of science are critically examined and when the profile of the scientist involved is defined. The optimism of Carlos Lacaz with regard to the solution of the problems of his field was incomparably beyond that of those who, immediately presume their solution is the final one with no discussion at all. Such a comparison for Carlos Lacaz is impossible because of his personal good sense and his intelligence, dignifying characteristics with which he ennobled his daily routine, with the indispensable sense of due proportion and wise humility always being present in him.

When one accompanies Carlos Lacaz's scientific activity, what one discovers is the permanent discipline of intellectual dedication and the value of experimental labour in the constant quest for the true features of scientific creation. We may here recall Rodin's well-known dictum: Do not rely on inspiration, because it does not exist. The only qualities of the artist and the scientist* are wisdom, concentration, sincerity and will-power. Fulfil your task like honest workmen.

An old Indian saying has it that there are three kinds of workmen: those who use both hands to carry out their tasks, forgetful of whatever may be going on around them; those who work with one of their hands while using the other to beat on a drum (the English equivalent of blowing one's horn!) to call attention to themselves, and those who use both their hands to beat the drum. Carlos Lacaz was a born member of the first group; unconcerned as he always was about spectacles of gross exhibitionism and far removed from superficial amateurism, he always fought against "scientific" postures based on prescientific intellectual structures.

He recognized constantly that we must impose certain limitations so as to better define what is acceptable and what is unacceptable in science and he thus lived out a permanent concern with the ethical and social implications of research, both as a researcher and as a teacher. As a teacher he insisted that we should never forget the content of bioethics whereby one studies the preservation of life with dignity, without, however, setting aside the freedom of each individual, whether in terms of freedom or of responsibility and, further, without forgetting the need for the establishment of minimal levels of risk to human life. He used to say: "the difficulty in ethical terms is in the appraisal of a situation of risk, the consequences of which may only become evident in the long term". We always agreed, he and I, that the important role of the scientist, beyond obstinate dedication to his work, is to know how to deal with such situations.

There is the constant need to bar the "non-moral" use of new knowledge without, however, permitting unwelcome, outside interference with the activity of scientists in general and especially with that of the true scientific specialist. With specialization, what was previously superficial and possibly sterile conjectur, is perceived as a notion of more intimate 
meaning from which it becomes possible to extract results of practical value. The process must involve individuals guided by good-sense, those who seek knowledge by means of consistent understanding. Individuals such as Carlos Lacaz, a true specialist, who lived with a permanent concern to extend the frontiers of his knowledge and to get through to specifics, showing an attitude that has always been for us a cause of particular appreciation. To our understanding, he consistently adopted this attitude and if such attitude constituted the foundation of our educational system, we should be much better off than at present, gaining in personality what we might lose in the consequent restriction of individual freedom.

Carlos Lacaz was always a most exceptional example of intelligence, good sense and humility, a person for whom his scientific ability was a true speciality and not just a "mania". Such exceptional individuals should be taken as examples, as valuable contributors characterized by that generosity which enables us to appreciate the specialties of others and respect them, knowing that everything in the scientist's calling contributes to one common task. Those excesses of verbal elaboration which strive to make us believe that they are the only solid basis on which affirmative and corrective reasoning may be based seem to us to be of little or no value. Such excesses go so far, perchance, as to be considered particularly useful as reactions and as such, stimulating to our knowledge...

It was against all this that Carlos Lacaz always fought, beating back the furies of turbulent amateurism, an amateurism that was capable of conserving dense deposits of beliefs, always ready to express themselves in the guise of doubts about what others think and do. For his permanent fight and constant help, Carlos Lacaz was an excellent, true and outstanding example.

José Alberto Neves Candeias Prof. Titular do Instituto de Ciências Biomédicas Laboratório de Virologia - USP 